\title{
MALAYSIAN JOURNAL OF LEARNING AND INSTRUCTION \\ http://e-journal.uum.edu.my/index.php/mjli
}

How to cite this article:

Suamuang, W., Easter, M. A., \& Suksakulchai, S. (2021). Relations between instructor feedback, self-regulation, assignment completion and academic achievement in Thai higher learning institutions. Malaysian Journal of Learning and Instruction, 18(1), 85-109. https://doi. org $/ 10.32890 / \mathrm{mjli2} 2021.18 .1 .4$

\section{RELATIONS BETWEEN INSTRUCTOR FEEDBACK, SELF-REGULATION, ASSIGNMENT COMPLETION AND ACADEMIC ACHIEVEMENT IN THAI HIGHER LEARNING INSTITUTIONS}

\author{
${ }^{1}$ Wuttiporn Suamuang, ${ }^{2}$ Surachai Suksakulchai \& \\ ${ }^{3}$ Matthew A. Easter \\ ${ }^{1}$ Learning Innovation and Technology Program \\ ${ }^{2}$ Department of Electrical Technology Education \\ King Mongkut's University of Technology Thonburi \\ Bangkok, Thailand \\ ${ }^{3}$ University of Missouri, Columbia, USA \\ ${ }^{2}$ Corresponding author: surachai@mail.kmutt.ac.th
}

\begin{abstract}
Purpose - Assignments have been linked with various benefits, including a higher quality of learning and academic achievement. The purpose of this study was to explore the relationship between assignment completion and academic achievement in higher education. Specifically, it investigated the impact of instructor feedback and three constructs of self-regulation (selfefficacy, time management, and help-seeking) on assignment completion (time spent on assignments and number of assignments completed) and academic achievement.
\end{abstract}

Methodology - The study employed a correlational research design and a selfreport survey. Data was collected from 1,106 undergraduate students in six 
universities in Thailand through a convenience sampling approach. Structural equation modelling was used to establish the strength of the relationships among the constructs of the model.

Findings - The number of assignments completed was found to have a strong association with academic achievement. Time management was the strongest predictor of the number of assignments completed as well as time spent on assignments. Time management was also the mediator between self-efficacy and the number of assignments completed. However, help-seeking was negatively associated with both the number of assignments completed and academic achievement.

Significance - These results have educational implications, and should be helpful for instructors, instructional designers and educators who may use the information to offer undergraduate students appropriate learning tools, strategies and environments for supporting assignment completion and academic achievement.

Keywords: Academic achievement, assignment completion, help-seeking, Thai higher education, time management, self-efficacy.

\section{INTRODUCTION}

Homework assignments have been viewed as a helpful practice for centuries, and are integrated into the learning and assessment of most academic courses (Vatterott, 2018). Instructors often use assignments, including homework, as an instructional tool for reflection, and for determining students' learning. Studies conducted at the post-secondary level have concluded that homework assignments help students to promote the quality of their learning (Zhu \& Leung, 2012), check their understanding of course materials (Koban et al., 2020), recall old materials (Beagley \& Capaldi, 2020) and learn from their mistakes (Grodner \& Rupp, 2013). In Thai higher education, research evidence supports the significance of homework assignments. Thai students perceive homework assignments in terms of maintaining their learning and acquisition of knowledge and skills (Songsirisak \& Jitpranee, 2019). Past studies confirm that college students who complete more assignments are more likely to gain higher academic accomplishment (Planchard et al., 2015; Ratniyom et al., 2019). Therefore, assignments are often at the centre of courses and university policies because of their importance (Doyle, 2008); most universities implement a policy on incomplete or late submission of assignments that would affect students' academic performance. 
Notwithstanding, assignment completion may be challenging for undergraduate students who are faced with difficulties in controlling their self-study (van der Meer et al., 2010; Nilson, 2013). Some students cannot complete assignments because of various obstacles (Dembo, 2013; Kaewkeaw, 2015). Li et al. (2018) found that 25 percent of freshmen in the United States undertaking engineering courses completed less than 80 percent of homework because of poor time management. Some college students encounter multiple, complex and prolonged tasks, leading to a poorly balanced workload (Ragupathi \& McMorran, 2016) and uncompleted homework assignments (Kaewkeaw, 2015; Planchard et al., 2015). In Thailand, Intrayut et al. (2013) reported problematic behaviours in undertaking homework assignments. Due to the inability to complete homework assignments by themselves, some Thai students prefer to copy assignments from friends. Songsirisak and Jitpranee (2019) found that plagiarism in assignments occurred at a rate of about 40 percent among Thai students. Hence, they recommended that students should know "how to complete their tasks by not copying others" (Songsirisak \& Jitpranee, 2019, p. 14). For these reasons, the purpose of this study was to seek an understanding of factors that improve assignment completion among undergraduate students, which in turn, should enhance their academic achievement, in line with related theory and empirical literature.

Previous studies have established that assignment completion, in terms of the number of assignments completed and time spent on assignments, is associated with academic achievement (Kontur et al., 2015; Planchard et al., 2015; Trout, 2018). However, few studies have investigated this relationship in higher education. Besides, most of the research thus far has been conducted in the USA with small samples and in specific subject areas. For instance, Planchard et al. (2015) investigated homework among 31 students studying genetics. Their results indicated that homework completed had a positive influence on academic achievement. Kitsantas and Zimmerman (2009) assessed 223 college students, also in the USA. They found that homework quality (i.e., the amount of homework completed) positively influenced students' grades. Cook (2018), on the other hand, found that devoting more time to homework led to lower grades in a biology course. The current study aimed to fill the gap in knowledge about this relationship with regards to Asian undergraduates, particularly Thai students, in an interdisciplinary context.

In general, homework is defined as "tasks assigned to students by school teachers that are meant to be carried out during non-school hours" (Cooper, 1989 , p. 7). In the present study, however, assignments refer to homework or coursework assigned by university instructors, either inside or outside the 
classroom. These assignments may be used for the purpose of evaluating students' outcomes and as part of the final course grade.

\section{THEORETICAL FRAMEWORK}

The theoretical background of the current research is self-regulation theory, which refers to the process of generating and maintaining thoughts, feelings and actions. This process is planned and cyclically applied for the accomplishment of individual goals (Zimmerman, 2000) such as assignment or coursework completion (Locke \& Latham, 1991). Evidence of self-regulation has been documented in relation to homework assignments. For instance, Bembenutty and Zimmerman (2003) revealed that at-risk college students who participated in a programme of self-regulation were more apt to complete homework. Using the self-regulatory process is essential to increase deep engagement with homework and to lessen the delay of gratification (Steiner, 2016).

The present study, based on Zimmerman and Moylan's (2009) model, is rooted in a social cognitive perspective. Zimmerman and Moylan propose three cyclic phases of self-regulation: forethought, performance and reflection. The forethought phase involves the preparation and use of motivation, action and strategies employed towards the performance phase. Believing in one's own abilities to put in an effective performance toward specific tasks leads to performing the tasks effectively. Self-efficacy is a part of motivational belief for decisions to engage in specific tasks and for behaviour guidance applied to achieve the goal (Eccles \& Wigfield, 2002). The performance phase is an implementation of planning that involves using strategies toward the tasks effectively (Schunk \& Greene, 2017). Students need to utilise different strategies such as time management and help-seeking (Zimmerman \& Moylan, 2009) to focus on their tasks and eliminate distractions (Zimmerman, 2000). The third phase is self-reflection. It refers to evaluating personal performance and reviewing one's own behaviour affecting the outcomes (Zimmerman, 2000). This study focuses on three constructs of self-regulation, namely time management, help-seeking and self-efficacy, to support assignment completion. Evidence suggests that each of these three factors of self-regulation would have an enormous influence on students' assignment completion (Hong et al., 2016; Li et al., 2018) and academic achievement (Bembenutty \& White, 2013).

According to self-regulation literature, one of the factors that makes selfregulation more effective is reliance on the social component such as instructors and parents to control individual actions and thoughts (Schunk \& 
Usher, 2017). Hence, assignment completion and the cyclical process may be influenced by monitoring from adults. For example, instructors offer verbal or written praise such as "excellent" or "great" on homework completed (Letterman, 2013). Nevertheless, as empirical evidence suggests that parents are less involved in college homework assignments (Letterman, 2013), the present study only looks at instructor feedback.

\section{LITERATURE REVIEW}

\section{Assignment Completion}

Assignments are commonly positively related to academic achievement. In the online learning context, Richards-Babb et al. (2011) used homework instead of quizzes to examine the success rate in a chemistry course. They found that homework can enhance the success rate, as measured by grades. Similarly, Ratniyom et al. (2019) reported that online homework scores positively affected students' grades in the Thai context. Phumchumphon (2006) investigated the components of good homework assignments in many subject areas and explored the impact of homework assignments on learning achievement among high school students. They reported that homework assignment procedures, including doing them, impacted students' academic achievement. In the current study, assignment completion refers to two aspects: the number of assignments completed and the time spent on assignments.

There are currently a limited number of studies on assignment completion conducted in higher education. Many of these have been conducted in the USA (e.g., Kontur et al., 2015; Li et al., 2018), and in specific subject areas such as biology (Cook, 2018) and genetics (Planchard et al., 2015). Several factors have been identified as influencing the amount of homework students completed and the time spent on homework. These include time management (Li et al., 2018), motivation (Planchard et al., 2015), aptitude (Kontur et al., 2015), class duration and instructor evaluations (Trout, 2018), and delay of gratification and self-regulation (Bembenutty \& Zimmerman, 2003). However, Songsirisak and Jitpranee (2019) observe that there is still a shortage of homework assignment research within the Thai context, and that previous studies have focused on elementary and secondary school levels.

\section{Time Management and Help-Seeking}

Time management involves setting, planning and managing time to accomplish academic tasks on time (Zimmerman \& Moylan, 2009). Over 60 percent of the 
students in Songsirisak and Jitpranee (2019)'s study reported that homework assignments could not be an obstacle in managing their free time. Good time management can improve academic success (Kitsantas, Cheema \& Wave, 2008). Students would better understand the content by spending more quality time on tasks. Li et al. (2018) found that poor time management skills led to a lower amount of homework completed. Studies conducted at the high school level also attach great importance to time management. For example, $\mathrm{Xu}$ (2011) pointed out that homework management, including managing time, plays a positive role in the amount of homework completed. Xu et al. (2014) identified that time management also impacted the time spent on homework.

Help-seeking is another key self-regulation strategy deemed significant for achieving specific performance. Bembenutty and White (2013) suggest that the self-regulation process brings about effectiveness in homework completion among college students. Students may need to seek some assistance to be able to complete their tasks or to achieve satisfactory performance (Karabenick \& Dembo, 2011), especially low-ability students (Koban et al., 2020). Thai students who encounter difficulty in doing assignments also tend to require help from their peers (Songsirisak \& Jitpranee, 2019). However, no study has examined the relationship between help-seeking and assignment completion in higher education.

\section{Self-Efficacy}

Self-efficacy is described as beliefs about individuals' competence to plan, arrange and perform a particular goal (Schunk \& Greene, 2017). If students are certain of their capability, they tend to endeavour to perform given tasks better (Schunk \& Greene, 2017) and achieve higher academic success (Siriparp, 2015) as well as better performance (Hetthong \& Teo, 2013). Research in both high school and higher education contexts has discovered that selfefficacy strongly influences homework achievement, including homework completion (Bembenutty \& Zimmerman, 2003; Hong et al., 2016). Selfefficacy has been found to be weakly related to time spent on mathematics homework in secondary school (Kitsantas et al., 2011). Self-efficacy not only plays a significant role in achieving homework completion, but also has an association with self-regulated strategies (Abdullah, 2016). It also links positively with time management among college students with low grades or low college entrance scores (Bembenutty, 2009). Similarly, research has also indicated that Thai students with high self-efficacy often use self-regulatory strategies, including time management and help-seeking (Thongnoum, 2002). With regards to help-seeking, a positive association has been found between academic self-efficacy and help-seeking in secondary schools (Sharma \& 
Nasa, 2016). However, recent evidence has revealed a negative relationship (Williams \& Takaku, 2011) or no relationship (Sakiz, 2011) between selfefficacy and help-seeking among college students.

\section{Instructor Feedback}

Many studies on instructor feedback in Thailand have focused on writing development (e.g., Tangkiengsirisin \& Kalra, 2016). However, investigations of homework assignments within the general area of instructor feedback are limited in number. Most of the literature on homework assignment behaviours have been based on investigations at elementary and secondary levels (e.g., Núñez et al., 2015; Xu, 2011). Núñez et al. (2015) demonstrated that providing feedback raised the amount of homework completed and the quality of homework time management. Their results also found no association between teacher feedback and time spent on homework. In higher education, instructor feedback also helps students to raise their academic performance (Brown et al. 2016). Feedback from instructors enables students to cope better with time management (Steiner, 2016) and self-efficacy (Brown et al., 2016). Teacher feedback and encouragement can strengthen students' self-efficacy (Schunk $\&$ Greene, 2017) and navigate students' further learning (Brown et al., 2016).

Considering the literature to date, the current study is quite distinct in that it concentrated on multiple factors associated with assignment completion and academic achievement. The study was conducted outside the USA, with a larger sample. Furthermore, it addressed the gaps in previous studies on homework, many of which have been conducted at secondary and elementary levels as opposed to post-secondary level. See Bas, Senturk and Cigerci (2017) for a review of literature on homework at secondary and elementary levels). Accordingly, this study explored the associations of academic achievement, number of assignments completed, time spent on assignments, time management, help-seeking, self-efficacy and instructor feedback.

The following research questions were shaped based on background theory and literature, as illustrated in Figure 1:

- What are the relationships between instructor feedback, students' selfefficacy, time management, help-seeking, time spent on assignments, number of assignments completed and academic achievement?

- What aspects of instructor feedback, self-efficacy, help-seeking, time management, time spent on assignment and number of assignments completed influence academic achievement among undergraduate students? 


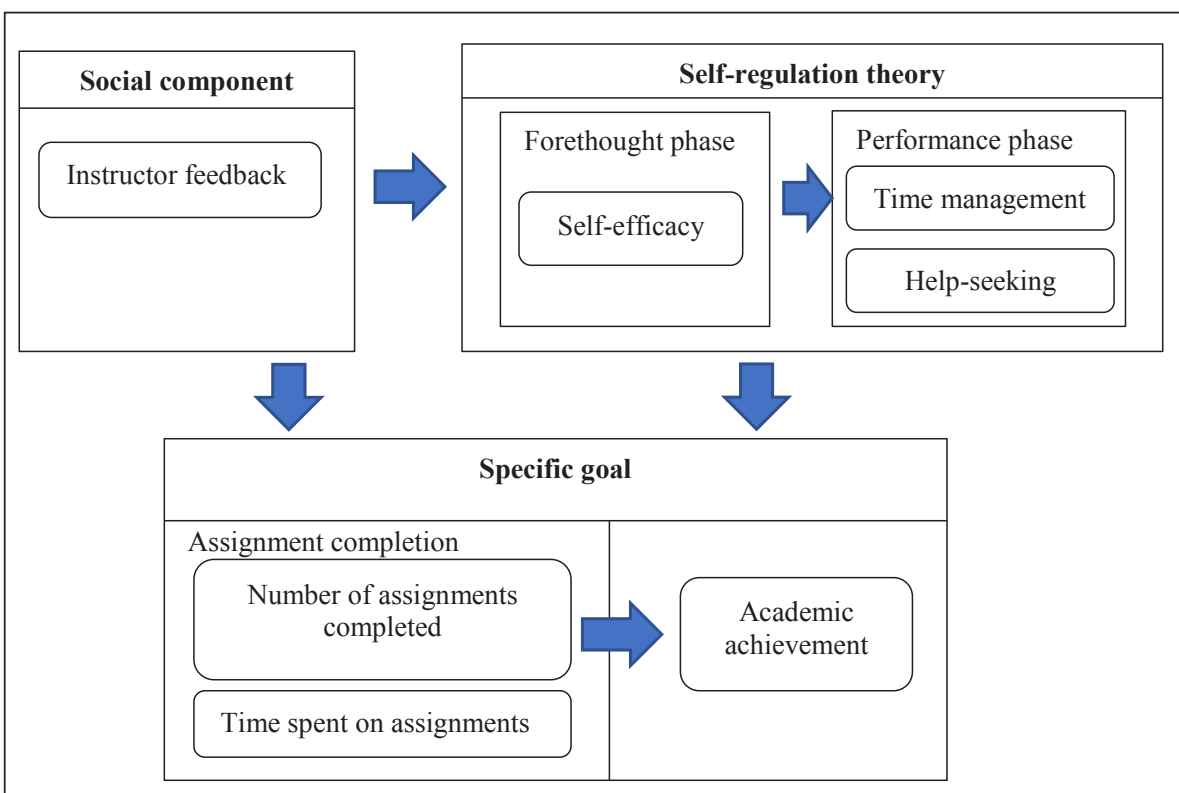

Figure 1. The theoretical framework that shaped the research questions.

\section{METHODOLOGY}

\section{Participants}

The study focused on investigating the influence of multiple factors on assignment completion and academic achievement among undergraduate students as a whole. When using path analysis to answer research questions, the minimum sample size should be more than 500 participants, based on a complexity model with numerous constructs $(>7)$ (Hair et al. 2010). This study involved 1,106 undergraduates, 405 males (37\%) and 701 females (63\%) from first year to fourth year, from six universities in Thailand. The participants were chosen using a convenience sampling approach. They were studying in different majors relating to science $(61 \%)$ and social studies $(49 \%)$, such as education, humanities and social science.

\section{Measures}

The study was based on a self-report survey to measure students' perceptions regarding six constructs: instructor feedback, self-efficacy, time management, help seeking, time spent on assignments and number of assignments completed. The survey comprised nineteen items, excluding gender, academic major and 
GPA, adapted from widely used measures in relevant past research. Three language experts used the back-translation method to translate the English items into Thai. Then, a pilot study involving 300 participants was conducted.

\section{Constructs}

\section{Instructor feedback (IF)}

IF included three items referring to feedback provided by instructors on students' assignments. The items and scale $(\alpha=.67)$ were adapted from Xu (2011). An example of an IF item is "My instructor checks this much of my assignments..."

\section{Self-efficacy (SE)}

SE was measured in terms of perceiving students' abilities in doing assignments. Five items $(\alpha=.83)$ from the Patterns of Adaptive Learning Scales (Midgley et al., 2000) were utilised. The rating scale ranged from 5 (very confident) to 1 (not confident at all). An example of an SE item is "I am certain I can figure out how to do the most difficult assignments."

\section{Help-seeking (HS)}

HS was measured by two items adapted from the Motivated Strategies for Learning Questionnaire (Pintrich, 1991; $\alpha=.72$ ). Students were asked about perceptions on seeking help from other people, or sources of help when facing obstacles while doing assignments (e.g., "When I cannot understand the material in assignments, I ask another student in this class for help").

\section{Time management (TM)}

TM comprised four items to assess how well students managed their time and schedules when doing assignments $(\alpha=.76)$. The items were from the Homework Management Scale (HMS; Xu, 2008). An example of a TM item is "I prioritise my work and plan in advance."

\section{Number of assignments completed (NC)}

Students were asked to report NC only in their major academic subject $(\alpha=.66)$. Three items, borrowed from Xu (2011) assessed how often students completed this number of assignments. IF, HS, TM, and NC items were measured using a five-point Likert scale from 1 to 5, denoting none to all, respectively.

\section{Time spent on assignments (TS)}

Three items from $\mathrm{Xu}$ (2011) were used to measure TS, specifically the amount of time spent on assignment completion daily, in a typical week and on a typical weekend $(\alpha=.66)$. These three items were measured on a Likert type scale of 1 to $5(5=$ more than 2 hours; $4=$ between 1.30 and 2 hours; $3=$ between 1 and 1.30 hours; 2 = between 30 minutes and 1 hour; and $1=$ less than 30 minutes). 


\section{Academic achievement (AA)}

AA was derived from students' self-report of their GPA in the previous semester, based on the following scale: $5=3.51-4.00,4=3.01-3.50,3=$ $2.51-3.00,2=2.00-2.50$, and $1=$ less than 2.00 .

\section{Procedure}

The principal investigator gained approval from the universities to collect data from the respondents. Before responding to the survey, the students were informed about the meaning of each construct, the definition of assignments, how to respond and their participation in this study as volunteers. Any student could refuse to participate, without any repercussions. To ensure that they were comfortable and able to provide their most truthful perception, the participants answered the questions on paper anonymously. They spent fifteen to thirty minutes to complete the survey in their major academic class.

\section{Data Analysis}

The study employed both descriptive and inferential statistics. Descriptive statistics provided information for checking assumptions; Pearson correlations allowed for the evaluation of interrelationships and multicollinearity; and the relationship between observed and latent variables was identified using Confirmatory Factor Analysis (CFA). This also provided information about the validity and reliability of the measurement model. Structural Equation Modelling (SEM) was used to assess the dataset to discover the strength of the relationships among latent variables in the model.

Construct validity of the measurement model was analysed through CFA. It comprised two dimensions: convergent and divergent validity. The indicators of convergent validity are Average Variance Extracted (AVE) and Construct Reliability (CR). Based on the rule of thumb, the standard value of AVE should be higher than .5 , while CR should be greater than .69 for good reliability, or between .6 and .7 for acceptable reliability (Hair et al., 2010). For discriminant validity, a comparison of the AVEs with the Maximum Shared Variance (MSV) and Average Shared Variance (ASV) was conducted. All AVEs of each construct should be higher than their MSV and ASV (Fornell \& Larcker, 1981).

SEM allows for the evaluation of a structural relationship among six constructs and an observed variable. These results could explain the effects of each relation, including direct, indirect, and total effects, strongest predictors, and intervening variables. Bootstrapping was used to "assume the symmetry 
or normality of the sampling distribution of the indirect effect" (Preacher \& Hayes, 2008, p. 884). This study bootstrapped 3,000 samples with 95 percent confidence interval to observe the significance of indirect effects. Nevertheless, Hair et al. (2010) suggested cut-off points of good fit indices to assess the validity of a structural model: if the number of samples was above 250 and the number of observed variables was between 13 to 29 items, the value indices should be $X^{2}=$ significant, RMSEA $<.07$ with CFI/TLI $>.92$. In the same way as SEM, CFA values were determined based on these criteria.

\section{RESULTS}

\section{Scale Validation}

Before the SEM analysis, the measurement of construct validity and reliability were performed by CFA and Cronbach's alpha, as shown in Table 1. The CFA model provided goodness of fit indices measured by the $X^{2}(136,1,106)$ $=253.69$, RMSEA of .03, CFI of .98, and TLI of .97. The assessment of reliability indicated acceptable Cronbach's values for all constructs $(\alpha=0.72$ 0.83 ) except IF, TS, and NC. These three constructs showed low reliability, perhaps because the constructs had few items. Taber (2018) suggested that alpha tends to increase with the increase in the number of instrument items. However, the internal consistency of all constructs was also checked by CR, and represented acceptable reliability. AVEs of NC, TS and HS were above or equal to .5. Another scale (IF, SE, and TM) of AVEs had an adequate value for convergent validity, as Fornell and Larcker (1981) recommended that when $\mathrm{AVE}$ is below 0.5 but $\mathrm{CR}$ is greater than 0.6 , the convergent validity of the construct is still acceptable. When comparing the AVEs of each construct with their CR, the results showed that the CR of each construct was greater than their AVE. The results of divergent validity indicated that all AVEs for the individual construct were higher than their MSV and ASV, leading to a real difference in a construct from other constructs.

\section{Table 1}

Construct Validity and Reliability of the Study

\begin{tabular}{ccccccccc}
\hline Constructs & $\begin{array}{c}\text { Cronbach's } \\
\text { alpha }\end{array}$ & Reliability & \multicolumn{2}{c}{$\begin{array}{c}\text { Convergent } \\
\text { validity }\end{array}$} & \multicolumn{3}{c}{$\begin{array}{c}\text { Divergent validity/ } \\
\text { Discriminant validity }\end{array}$} \\
& CR & AVE & CR>AVE & MSV & ASV & MSV<AVE & ASV<AVE \\
\hline $\begin{array}{c}\text { 1. Instructor } \\
\text { feedback }\end{array}$ & 0.67 & 0.68 & 0.42 & $\checkmark$ & 0.16 & 0.09 & $\checkmark$ & $\checkmark$ \\
\hline
\end{tabular}

(continued) 


\begin{tabular}{lcccccccc}
\hline Constructs & $\begin{array}{c}\text { Cronbach's } \\
\text { alpha }\end{array}$ & Reliability & \multicolumn{1}{c}{$\begin{array}{c}\text { Convergent } \\
\text { validity }\end{array}$} & \multicolumn{4}{c}{$\begin{array}{c}\text { Divergent validity/ } \\
\text { Discriminant validity }\end{array}$} \\
\hline $\begin{array}{l}\text { 2. Self-efficacy } \\
\text { 3. Help-seeking }\end{array}$ & 0.83 & 0.82 & 0.49 & $\checkmark$ & 0.15 & 0.07 & $\checkmark$ & $\checkmark$ \\
$\begin{array}{c}\text { 4. Time- } \\
\text { management }\end{array}$ & 0.76 & 0.72 & 0.56 & $\checkmark$ & 0.16 & 0.06 & $\checkmark$ & $\checkmark$ \\
$\begin{array}{c}\text { 5. Time spent on } \\
\text { assignments }\end{array}$ & 0.66 & 0.67 & 0.50 & $\checkmark$ & 0.07 & 0.03 & $\checkmark$ & $\checkmark$ \\
$\begin{array}{c}\text { 6. Number of } \\
\text { assignments } \\
\text { completed }\end{array}$ & 0.66 & 0.67 & 0.50 & $\checkmark$ & 0.16 & 0.07 & $\checkmark$ & $\checkmark$ \\
\hline
\end{tabular}

Note: $\mathrm{CR}=$ Construct Reliability, AVE $=$ Average Variance Extracted, MSV $=$ Maximum Shared Variance, ASV = Average Shared Variance

\section{Descriptive Statistics and Correlations}

The correlations and descriptive statistics for all constructs are listed in Table 2. From the assumption analysis, there was no missing data; violations of normality did not appear in terms of skewness and kurtosis (from .11 to .87 absolutely). Multivariate outliers were checked by Mahalanobis distance, and 13 outliers were found and deleted from the dataset. Pearson correlations were used to evaluate the relationship of all constructs, and results ranged from weak to moderate relationships $(r=0.06-0.31)$, representing nonmulticollinearity (Hair et al., 2010). Among the constructs, IF and TM had the strongest relationship $(r=.31, p<.001)$. The constructs shared $9.67 \%$ of their variances, representing a medium effect (Cohen, Manion \& Morrison, 2018). HS had the lowest significance related to $\mathrm{NC}, r=.06, p<.05$. The constructs shared $.40 \%$ of their variances, representing a small effect. All constructs were associated with each other except for two pairs: SE and TS; and HS and AA.

\section{Table 2}

Descriptive Statistics and Correlations among Latent Variables

\begin{tabular}{lccccccc}
\hline Construct & 1 & 2 & 3 & 4 & 5 & 6 & 7 \\
\hline 1. Instructor feedback (IF) & 1 & - & - & - & - & - & - \\
2. Self-efficacy (SE) & $.26^{* * *}$ & 1 & - & - & - & - & - \\
3. Help-seeking (HS) & $.20^{* * *}$ & $.13^{* * *}$ & 1 & - & - & - & - \\
$\begin{array}{l}\text { 4. Time management (TM) } \\
\text { 5.Time spent on }\end{array}$ & $.31^{* * *}$ & $.30^{* * *}$ & $.30^{* * *}$ & 1 & - & - & - \\
$\quad$ & $.08^{* *}$ & .06 & $.10^{* *}$ & $.17^{* * *}$ & 1 & - & - \\
$\begin{array}{l}\text { 6. Numbignments (TS) } \\
\quad \text { Completed (NC) }\end{array}$ & $.20^{* * *}$ & $.10^{* *}$ & $.06^{*}$ & $.29^{* * *}$ & $.17^{* * *}$ & 1 & - \\
\hline
\end{tabular}




\begin{tabular}{lccccccc}
\hline Construct & 1 & 2 & \multicolumn{1}{c}{3} & \multicolumn{1}{c}{4} & 5 & 6 & 7 \\
\hline $\begin{array}{l}\text { 7. Academic achievement } \\
\text { (AA) }\end{array}$ & $.15^{* * *}$ & $.11^{* * *}$ & -.01 & $.20^{* * *}$ & $.13^{* * *}$ & $.35^{* * *}$ & 1 \\
Mean & & & & & & & \\
SD & 4.03 & 3.57 & 3.78 & 3.96 & 3.77 & 4.11 & 3.52 \\
Skewness & .64 & .62 & .71 & .59 & .86 & .79 & 1.00 \\
$\quad$ Kurtosis & -.60 & -.11 & -.31 & -.40 & -.54 & -.87 & -.21 \\
$* p<.05, * * p<.01, * * * p<.001$ & .42 & -.20 & .19 & .27 & -.22 & .61 & -.74 \\
\hline
\end{tabular}

\section{SEM Analysis}

The SEM approach was used to estimate multiple and interrelated associations pertaining to the second research question. The study identified SE, HS, TM, $\mathrm{TS}$, and NC measures as independent, dependent or intervening variables, IF as an independent variable, and AA as a dependent variable.

The results of the SEM are illustrated in Figure 2. Using Maximum Likelihood methods, the statistics presented an excellent overall model fit, in which all values were within the criteria relating to a good model fit. The $X^{2}$ value was 280.51 with 149 degrees of freedom $(p<.001)$, normed $X^{2}=1.88$, and RMSEA $=0.03$ with a $90 \%$ confidence interval of .02 to .03 . Other values showed CFI of .98 and TLI of .97.

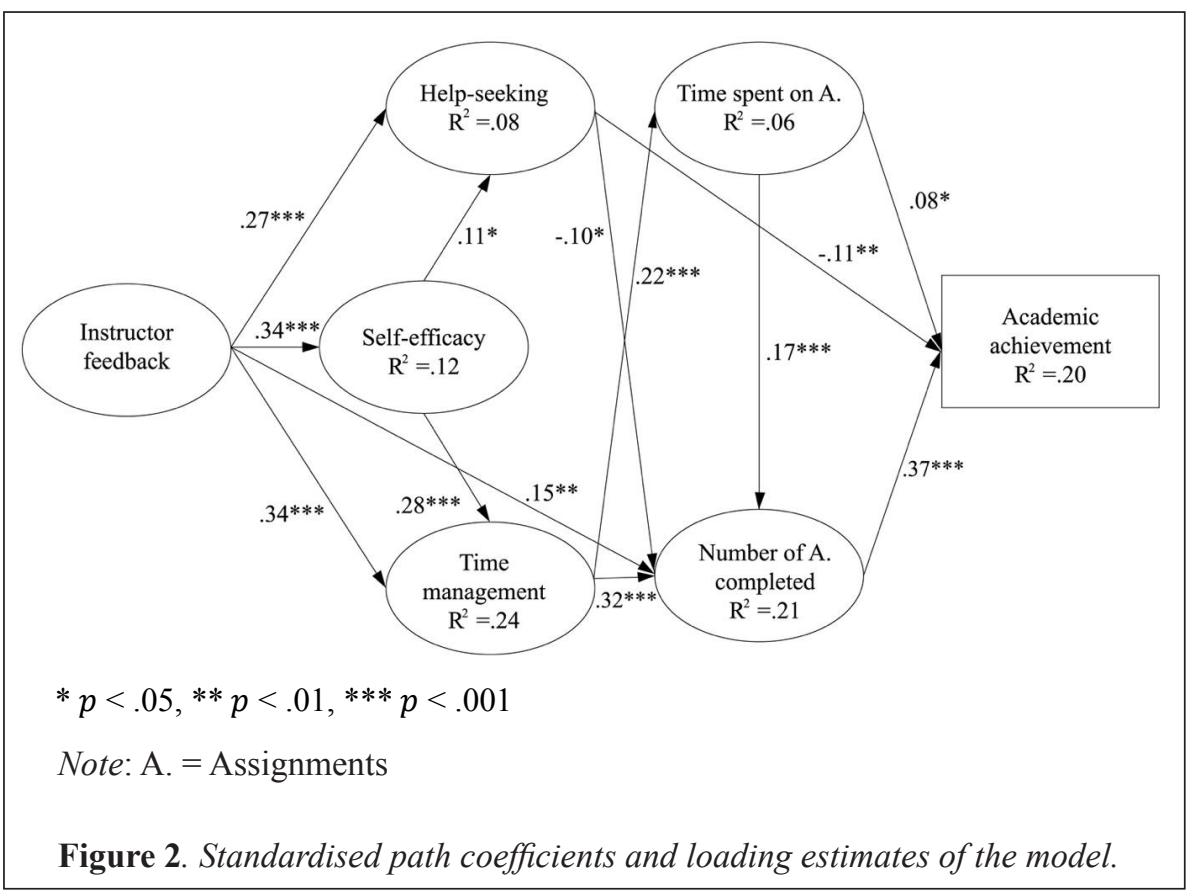




\section{Direct effects}

The strongest total effect on AA was $\mathrm{NC}(\beta=.37, p<.001)$. TS related positively to AA $(\beta=.08, p<.05)$, while HS had a negative association $(\beta=$ $-.11, p<.01)$. For NC and TS as dependent variables, TM was the strongest predictor $(\beta=.38, p<.001 ; \beta=.22, p<.001$, respectively). The findings also demonstrated that IF also strongly predicted TM $(\beta=.41, p<.001)$, compared with HS $(\beta=.23, p<.001)$ and SE $(\beta=.34, p<.001)$. The influences of SE on HS and TM were statistically significant.

\section{Indirect effects}

The association between TM and AA was mediated $(\beta=.16, p<.001)$ by TS and NC. IF $(\beta=.13, p<.001)$ and SE $(\beta=.08, p<.05)$ had an indirect effect on AA with TM and HS as a mediator. Relating to NC and TS, both TM and HS were intervening variables between $\mathrm{SE}$ and $\mathrm{NC}(\beta=.10, p<.001)$. IF and $\mathrm{SE}$ had an indirect effect on TS through TM as an intervening variable. Table 3 summarizes the direct, indirect and total effects in the model.

SEM further demonstrated a medium effect size for AA (Cohen et al., 2018), explaining 20.4 percent of variability with $\mathrm{NC}$, TS, and HS. The model accounted for 21.3 percent and 5.9 percent of the variance in NC and TS, indicating medium and small effect sizes, respectively. The effect size of the variance in $\operatorname{HS}\left(R^{2}=.08\right), \mathrm{TM}\left(R^{2}=.24\right), \mathrm{SE}\left(R^{2}=.12\right)$ was small, medium, and small, respectively.

\section{Table 3}

Direct, Indirect and Total Effects

\begin{tabular}{llccc}
\hline & Effect & \multicolumn{2}{c}{ Standardized coefficient $(\beta)$} \\
\hline Independent variable & Dependent variable & Direct & Indirect & Total \\
\hline Instructor feedback & Self-efficacy & $.34 * * *$ & - & $.34 * * *$ \\
Instructor feedback & Help-seeking & $.23 * * *$ & $.04 *$ & $.26 * * *$ \\
Self-efficacy & Help-seeking & $.16^{*}$ & & $.11^{*}$ \\
Instructor feedback & Time management & $.31 * * *$ & $.11^{* * *}$ & $.41^{* * *}$ \\
Self-efficacy & Time management & $.28 * * *$ & - & $.28 * * *$ \\
Instructor feedback & Time spent on & - & $.09 * * *$ & $.09 * * *$ \\
& assignments & & & $.07 * * *$ \\
Self-efficacy & Time spent on & - & $.07 * * *$ \\
& assignments & & & \\
Time management & Time spent on & $.22 * * *$ & - & $.22 * * *$ \\
& assignments & & & \\
\hline
\end{tabular}




\begin{tabular}{|c|c|c|c|c|}
\hline \multicolumn{2}{|c|}{ Effect } & \multicolumn{3}{|c|}{ Standardized coefficient $(\beta)$} \\
\hline Independent variable & Dependent variable & Direct & Indirect & Total \\
\hline Instructor feedback & $\begin{array}{l}\text { Number of } \\
\text { assignments completed }\end{array}$ & $.15 * *$ & $.13 * * *$ & $.28 * * *$ \\
\hline Self-efficacy & $\begin{array}{l}\text { Number of } \\
\text { assignments completed }\end{array}$ & - & $.10 * * *$ & $.10 * * *$ \\
\hline Help-seeking & $\begin{array}{l}\text { Number of } \\
\text { assignments completed }\end{array}$ & $-.10 *$ & - & $-.10 *$ \\
\hline Time management & $\begin{array}{l}\text { Number of } \\
\text { assignments completed }\end{array}$ & $.34 * * *$ & $.04 * * *$ & $.38 * *$ \\
\hline $\begin{array}{l}\text { Time spent on } \\
\text { assignments }\end{array}$ & $\begin{array}{l}\text { Number of } \\
\text { assignments completed }\end{array}$ & $.17 * * *$ & - & $.17 * * *$ \\
\hline Instructor feedback & Academic achievement & - & $.13 * * *$ & $.13 * * *$ \\
\hline Self-efficacy & Academic achievement & - & $.08^{*}$ & $.08^{*}$ \\
\hline Help-seeking & Academic achievement & $-.11 * *$ & - & $-.11 * *$ \\
\hline Time management & Academic achievement & - & $.16^{* * *}$ & $.16^{* * *}$ \\
\hline $\begin{array}{l}\text { Time spent on } \\
\text { assignments }\end{array}$ & Academic achievement & $.08 *$ & $.07 * * *$ & $.14 * * *$ \\
\hline $\begin{array}{l}\text { Number of } \\
\text { assignments completed }\end{array}$ & Academic achievement & $.37 * * *$ & - & $.37 * * *$ \\
\hline
\end{tabular}

$* p<.05, * * p<.01, * * * p<.001$

\section{DISCUSSION}

This study found that both number of assignments completed and time spent on assignments had a positive relationship with academic achievement. In terms of number of assignments completed, the finding is consistent with Grodner and Rupp (2013) and Planchard et al. (2015), who discovered that students who completed homework assignments typically had higher test performance. The number of assignments completed possibly contributed to better scores on examinations as students would have had more opportunities to review their understanding and misconceptions of the content (Grodner \& Rupp, 2013). Meanwhile, the result in relation to time spent on assignments is inconsistent with some prior research in postsecondary (Cook, 2018) and secondary education (Núñez et al., 2015; Trautwein et al., 2009). For example, Cook's (2018) data revealed that an overall decline in course grade tended to raise the amount of time spent on homework, except for a middle course grade. This issue has been debated in various studies on homework assignments, although the results have been distinctive, i.e. positive, negative, and no significant results. A likely explanation for the results is that if students took considerable time on assignments, they were more likely to be clear about their conceptions of the content and knowledge (Richards-Babb et al., 2011). 
Surprisingly, an inverse relationship between help seeking and academic achievement was found in the current study. The finding is interesting in that it is incongruent with most of the past research. For instance, Bembenutty and White (2013) found that adaptive help-seeking served as an effective strategy for boosting final course grades. Butler (2006) noted that low-achieving students were less likely to ask for assistance for fear of being considered dumb compared with those with high academic achievement. However, our results may be explained by Komarraju and Nadler (2013), who suggested that students with higher GPAs were less likely to find assistance because they devoted their effort to regulation and carried on with their course work even when it was difficult or tedious.

The study also found predictions of other constructs, i.e., instructor feedback, self-efficacy and time management, on academic achievement through number of assignments completed as an intervening variable. Students with high instructor feedback, self-efficacy and time management were better able to constitute academic achievement when they could finish their assignments on time. Self-efficacy is known to promote students' grades (Bembenutty \& White, 2013). Thus, this study took into account the number of assignments completed as a crucial factor for supporting academic achievement. Nonetheless, instructor feedback (Brown et al., 2016), self-efficacy (Komarraju \& Nadler, 2013) and time management (Kitsantas et al., 2008) still directly affected academic achievement. Webb and Moallem's (2016) study demonstrated that students who received more positive comments from instructors tended to have higher academic performance.

With reference to the number of assignments completed as a dependent variable, time management was its strongest predictor compared with instructor feedback, help seeking, and time spent on assignments. This finding is congruent with self-regulation theory and prior research. Self-regulation theory claims that applying effective strategies on tasks helps students resist distractions (Zimmerman \& Moylan, 2009). Strategies such as time management can prevent students from procrastinating and help them to finish academic tasks by the due date (Wolterset al., 2017). Planchard et al. (2015) indicated that time commitment helps students to deal with complicated tasks or tasks that consume too much time. As for the other constructs, our findings seem to be in agreement with studies conducted at the secondary school level: the number of assignments completed was predicted by instructor feedback (Xu, 2011) and time spent on assignments (Núñez et al., 2015). It was also found that self-efficacy indirectly impacted on the number of assignments completed. This finding is consistent with self-regulation theory and previous studies (Bembenutty \& Zimmerman, 2003; Hong et al., 2016) that have shown 
that self-efficacy could assist students in completing homework. However, based on the theory, it is suggested that self-efficacy requires time management for assignments to be completed.

Another finding was that help seeking not only affected academic achievement negatively, but also the number of assignments completed. This result should be considered carefully and be applied in learning environments similar to this study. Conversely however, it may be interpreted that students with low number of assignments completed often require assistance because they are unable to complete their assignments by themselves (Koban et al., 2020). As there are few studies on the effect of help seeking on the number of assignments completed, this result provides new evidence for higher education.

The results also showed that time management was a predictor of time spent on assignments. This is partially consistent with Xu et al. (2014), who found that spending more time on homework was linked with better time management at the class level. However, time management negatively impacted time spent on assignments at the student level. Our findings also showed that instructor feedback and self-efficacy indirectly influenced time spent on assignments. With regards to self-efficacy, this finding is consistent with the self-regulation process in the forethought and performance phases (Zimmerman \& Moylan, 2009). Self-efficacy can assist students in acquiring effective performance such as time management. Pertaining to instructor feedback, however, results were inconsistent with Núñez et al. (2015), who found that teacher feedback was not a predictor of time spent doing homework. This finding may suggest that instructor feedback and self-efficacy alone may be insufficient to increase time spent on assignments, and therefore, should be combined with time management to help students spend more time on assignments. Accordingly, time management is essential to support both number of assignments completed as well as time spent on assignments.

\section{LIMITATIONS AND IMPLICATIONS}

Some limitations of the current study should be noted in order to consider their implications and future research directions. This study was based on selfreported measures, which serve as a flexible method of collecting evidence on various aspects of human behaviour. Nevertheless, inaccurate responses may be a disadvantage. For example, respondents can report their own behaviours in a positive light (Vanderstoep \& Johnson, 2009). In addition, some constructs had only two items; although acceptable, this may be considered as technically problematic. As this study used a quantitative measure, further studies may 
consider using other instruments such as interviews and observations to gain more in-depth knowledge. The variables in the current study deserve more scrutiny to obtain insights into how students manage their time and why help-seeking negatively affected the number of assignments completed and academic achievement.

The results of this study are relative to the Thai environment and assignments were perceived as a major issue for the participants. Thus, assignments were explored with an overall view from various subject areas such as computing and foreign languages. Although assignments in the study represented both formative and summative assessments that were included in the final grade, proportions of homework assessment may vary, depending on a particular course. Future studies could investigate a particular academic area (e.g., computer engineering) as well as identify the proportion of homework assessment in a specific course.

The current findings lead to a consideration of their educational implications. Assignment completion is not only a significant factor to drive students' academic achievement, but also to improve self-regulation, which are important strategies for overcoming obstacles in postsecondary school environments (Hensley et al., 2015). The results contribute original insights into the homework assignment issue in Thai higher education. No research so far has focused on the complex associations between instructor feedback, factors of self-regulation, assignment completion, and academic achievement concurrently. In addition, this study produced different results regarding help seeking, compared with other studies. Thus, instructors may employ such information to better understand the factors influencing assignment completion and academic achievement so that they can develop more suitable teaching approaches for their students.

Having strong time management can increase the number of assignments completed. Instructional designers and instructors, therefore, may promote time management skills via teaching tactics such as using planners to make "goals and ranking activities in terms of importance" (Hensley et al., 2018, p. 117). Bembenutty and White (2013) suggested the use of homework logs to record data relating to homework, and instructors can offer students feedback. Collis et al. (2001) affirmed that providing feedback is useful not only for face-to-face assignments, but also web-based assignments. Instructors can use 'model answers' from the computer and use peer feedback to save instructors' time.

Self-efficacy was found to be a significant factor that supports the number of assignments completed and academic achievement. Instructors should design purposeful assignments to encourage students to recognise their abilities. The 
results also provide unique knowledge of the relationship of help seeking to number of assignments completed and academic achievement for Asian students, specifically for Thai students. The present findings showed that the more students sought help, the lower their academic achievement and number of assignments completed, suggesting that instructors should pay attention to help-seeking behaviour. When students ask for assistance often, it might indicate that they cannot undertake the assignments by themselves. Mostly, these students are lower academic achievers and do not understand the content. Instructors can use information search, which is a type of help seeking, to provide task-related information as an initiative for requiring assistance and to help students to complete their assignments on their own (Puustinen \& Rouet, 2009).

\section{ACKNOWLEDGMENT}

The authors thank the Petchra Pra Jom Klao, Ph.D. Research Scholarship, King Mongkut's University of Technology Thonburi, Thailand for the financial support of this study.

\section{REFERENCES}

Abdullah, M. (2016). Interaction effects of gender and motivational beliefs on self-regulated learning: A study at ICT-integrated schools. Malaysian Journal of Learning and Instruction, 13(1), 25-41.

Bas, G., Senturk, C., \& Cigerci, F. (2017). Homework and academic achievement: A meta-analytic review of research. Issues in Educational Research, 27(1), 31-50.

Beagley, J., \& Capaldi, M. (2020). Using cumulative homework in calculus classes. PRIMUS, 30(3), 335-348. https://doi.org/10.1080/10511970.2 019.1588814

Bembenutty, H. (2009). Academic delay of gratification, self-efficacy, and time management among academically unprepared college students. Psychological Reports, 104(2), 613-623. https://doi.org/10.2466/ pr0.104.2.613-623

Bembenutty, H., \& White, M. (2013). Academic performance and satisfaction with homework completion among college students. Learning and Individual Differences, 24, 83-88. https://doi.org/10.1016/j. lindif.2012.10.013

Bembenutty, H., \& Zimmerman, B. (2003, April). The relation of motivational beliefs and self-regulatory processes to homework completion and academic achievement [Paper presentation]. Annual Meeting of the American Educational Research Association, Chicago, IL. 
Brown, G., Peterson, E., \& Yao, E. (2016). Student conceptions of feedback: Impact on self-regulation, self-efficacy, and academic achievement. British Journal of Educational Psychology, 86(4), 606-629. https://doi. org/10.1111/bjep.12126

Butler, R. (2006). An achievement goal perspective on student help seeking and teacher help giving in the classroom: Theory, research, and educational implications. In S. Karabenick \& R. Newman (Eds.), Help seeking in academic setting: Goals, groups, and contexts (pp. 15-44). Lawrence Erlbaum.

Cohen, L., Manion, L., \& Morrison, K. (2018). Research methods in education (8th ed.). Routledge.

Collis, B., De Boer, W., \& Slotman, K. (2001). Feedback for web-based assignments. Journal of Computer Assisted Learning, 17(3), 306-313. https://doi.org/10.1046/j.0266-4909.2001.00185.x

Cook, D. (2018). The impact of online homework, time on homework, gender, and metacognition in improving student achievement in undergraduate Biology courses [Unpublished doctoral dissertation]. Liberty University.

Cooper, H. (1989). Homework. Longman.

Dembo, M. (2013). Motivation and learning strategies for college success: A self-management approach. Routledge.

Doyle, T. (2008). Helping students learn in a learner-centered environment: A guide to facilitating learning in higher education. Stylus Publishing.

Eccles, J., \& Wigfield, A. (2002). Motivational beliefs, values, and goals. Annual Review of Psychology, 53(1), 109-132. https://doi.org/10.1146/ annurev.psych.53.100901.135153

Fornell, C., \& Larcker, D. (1981). Evaluating structural equation models with unobservable variables and measurement error. Journal of Marketing Research, 18(1), 39-50. https://doi.org/10.1177/002224378101800104

Grodner, A., \& Rupp, N. (2013). The role of homework in student learning outcomes: Evidence from a field experiment. The Journal of Economic Education, 44(2), 93-109. https://doi.org/10.1080/00220485.2013.770 334

Hair, F., Black, W., Babin, B., \& Anderson, R. (2010). Multivariate data analysis. Pearson Education Limited.

Hensley, L., Shaulskiy, S., Zircher, A., \& Sanders, M. (2015). Overcoming barriers to engaging in college academics. Journal of Student Affairs Research and Practice, 52(2), 176-189. https://doi.org/10.1080/19496 591.2015 .1020246

Hensley, L., Wolters, C., Won, S., \& Brady, A. (2018). Academic probation, time management, and time use in a college success course. Journal of College Reading and Learning, 48(2), 105-123. https://doi.org/10.108 0/10790195.2017.1411214 
Hetthong, R., \& Teo, A. (2013). Does writing self-efficacy correlate with and predict writing performance? International Journal of Applied Linguistics and English Literature, 2(1), 157-167. https://doi. org/10.7575/ijalel.v.2n.1p.157

Hong, E., Mason, E., Peng, Y., \& Lee, N. (2016). Effects of homework motivation and worry anxiety on homework achievement in Mathematics and English. Educational Research and Evaluation, 21(7-8), 491-514. https://doi.org/10.1080/13803611.2015.1131721

Intrayut, S., Tansriwong, S., \& Koseeyaporn, P. (2013, November). A study of student behavior in homework assignment practicing in electric circuit analysis courses from Faculty of Technical Education and the College of Industrial Technology, King Mongkut's University Of Technology North Bangkok [Paper presentation]. 6th National Conference on Technical Education, King Mongkut's University of Technology North Bangkok, Thailand.

Kaewkeaw, P. (2015, March). Study of students' behavior in copying and not handing in homework or assignment in course information literacy skills, in the academic year 2013. [Paper presentation]. 7th NPRU National Academic Conference, Nakhon Pathom Rajabhat University, Thailand.

Karabenick, S., \& Dembo, M. (2011). Understanding and facilitating self-regulated help seeking. New Directions for Teaching and Learning, 126, 33-43. https://doi.org/10.1002/tl.442

Kitsantas,A.,Cheema,J.,\&Ware,H.(2011).Mathematics achievement:Therole of homework and self-efficacy beliefs. Journal of Advanced Academics, 22(2), 310-339. https://doi.org/10.1177/1932202X1102200206

Kitsantas, A., Winsler, A., \& Huie, F. (2008). Self-regulation and ability predictors of academic success during college: A predictive validity study. Journal of Advanced Academics, 20(1), 42-68. https://doi. org/10.4219/jaa-2008-867

Kitsantas, A., \& Zimmerman, B. (2009). College students' homework and academic achievement: The mediating role of self-regulatory beliefs. Metacognition Learning, 4(2), 97-110. https://doi.org/10.1007/s11409008-9028-y

Kline, R. (2016). Principles and practice of structural equation modeling (4th ed.). Guilford.

Koban, D., Fukuzawa, M., Slocum, R., Fletcher, M., \& Pleuss, J. (2020). Differential effects of incentivized homework on student achievement in undergraduate Mathematics. PRIMUS, 30(5), 501-519. https://doi.or $\mathrm{g} / 10.1080 / 10511970.2018 .1530703$

Komarraju, M., \& Nadler, D. (2013). Self-efficacy and academic achievement: Why do implicit beliefs, goals, and effort regulation matter? Learning and Individual Differences, 25, 67-72. https://doi.org/10.1016/j. lindif.2013.01.005 
Kontur, F., de La Harpe, K., \& Terry, N. (2015). Benefits of completing homework for students with different aptitudes in an introductory electricity and magnetism course. Physical Review Special TopicsPhysics Education Research, 11(1), 010105. https://doi.org/10.1103/ PhysRevSTPER.11.010105

Letterman, D. (2013). Students' perception of homework assignments and what influences their ideas. Journal of College Teaching \& Learning, 10(2), 113-122. https://doi.org/10.19030/tlc.v10i2.7751

Li, W., Bennett, R., Olsen, T., \& McCord, R. (2018). Engage engineering students in homework: Attribution of low completion and suggestions for interventions. American Journal of Engineering Education, 9(1), 23-38. https://doi.org/10.19030/ajee.v9i1.10186

Locke, E., \& Latham, G. (1991). A theory of goal setting \& task performance. Prentice-Hall.

Midgley, C., Maehr, M., Hruda, L., Anderman, E., Anderman, L., Freeman, K., \& Urdan, T. (2000). Manual for the patterns of adaptive learning scales. University of Michigan.

Nilson, L. (2013). Creating self-regulated learners: Strategies to strengthen students'self-awareness and learning skills. Stylus Publishing.

Núñez, J., Suárez, N., Rosário, P., Vallejo, G., Cerezo, R., \& Valle, A. (2015). Teachers' feedback on homework, homework-related behaviors, and academic achievement. The Journal of Educational Research, 108(3), 204-216. https://doi.org/10.1080/00220671.2013.878298

Phumchumphon, T. (2006). Development of indicators of good homework and influence of homework on student achivement [Unpublished master's thesis]. Chulalongkorn University, Thailand.

Pintrich, P. (1991). A manual for the use of the Motivated Strategies for Learning Questionnaire (MSLQ). The University of Michigan.

Planchard, M., Daniel, K., Maroo, J., Mishra, C., \& McLean, T. (2015). Homework, motivation, and academic achievement in a college genetics course. Bioscene, 41(2), 11-18.

Preacher, K. J., \& Hayes, A. F. (2008). Asymptotic and resampling strategies for assessing and comparing indirect effects in multiple mediator models. Behavior Research Methods, 40(3), 879-891. https://doi. org/10.3758/BRM.40.3.879

Puustinen, M., \& Rouet, J.-F. (2009). Learning with new technologies: Help seeking and information searching revisited. Computers \& Education, 53(4), 1014-1019. https://doi.org/10.1016/j.compedu.2008.07.002

Ragupathi, K., \& McMorran, C. (2016). Freedom and control in a gradeless learning environment. https://www.srhe.ac.uk/conference2016/ abstracts/0044.pdf

Ratniyom, J., Boonphadung, S., \& Unnanantn, T. (2019). Learning management based on online homework in organic chemistry course for pre-service 
science teachers: A case study of relationship between online homework scores and learning achievement. Journal of Educational Research of Faculty of Education, Srinakharinwirot University, 14(2), 43-57.

Richards-Babb, M., Drelick, J., Henry, Z., \& Robertson-Honecker, J. (2011). Online homework, help or hindrance? What students think and how they perform. Journal of College Science Teaching, 40(4), 81-93.

Sakiz, G. (2011). Mastery and performance approach goal orientations in relation to academic self-efficacy beliefs and academic help seeking behaviors of college students in Turkey. Educational Research, 2(1), 771-778.

Schunk, D., \& Greene, J. (2017). Handbook of self-regulation of learning and performance. Routledge.

Schunk, D., \& Usher, E. (2017). Social cognitive theoretical perspective of self-regulation. In B. Zimmerman \& D. Schunk (Eds.), Handbook of self-regulation of learning and performance (pp. 35-51). Routledge.

Sharma, H., \& Nasa, G. (2016). Association between academic self-efficacy, academic help-seeking behaviour and achievement among secondary school students. International Journal of Current Research, 8(12), 44455-44459.

Siriparp, T. (2015). Examining self-efficacy and achievement in an educational research course. Procedia-Social and Behavioral Sciences, 171, 13601364. https://doi.org/10.1016/j.sbspro.2015.01.254

Songsirisak, P., \& Jitpranee, J. (2019). Impact of homework assignment on students'learning. Journal of Education, Naresuan University, 21(2), $1-19$.

Steiner, H. (2016). The strategy project: Promoting self-regulated learning through an authentic assignment. International Journal of Teaching and Learning in Higher Education, 28(2), 271-282.

Taber, K. (2018). The use of Cronbach's alpha when developing and reporting research instruments in science education. Research in Science Education, 48(6), 1273-1296. https://doi.org/10.1007/s11165-0169602-2

Tangkiengsirisin, S., \& Kalra, R. (2016). Thai students' perceptions on the direct vs. indirect written corrective feedback: A Thai university context. Arab World English Journal (AWEJ), 7(3), 161-176. https:// doi.org/10.2139/ssrn.2859253

Thongnoum, D. (2002). Self-efficacy, goal orientations, and self-regulated learning in Thai students [Unpublished doctoral dissertation]. Oklahoma State University, USA.

Trautwein, U., Schnyder, I., Niggli, A., Neumann, M., \& Lüdtke, O. (2009). Chameleon effects in homework research: The homework-achievement association depends on the measures used and the level of analysis 
chosen. Contemporary Educational Psychology, 34(1), 77-88. https:// doi.org/10.1016/j.cedpsych.2008.09.001

Trout, B. (2018). The effect of class session length on student performance, homework, and instructor evaluations in an introductory accounting course. Journal of Education for Business, 93(1), 16-22. https://doi.org /10.1080/08832323.2017.1415196

van der Meer, J., Jansen, E., \& Torenbeek, M. (2010). It's almos t a mindset that teachers need to change: First-year students' need to be inducted into time management. Studies in Higher Education, 35(7), 777-791. https://doi.org/10.1080/03075070903383211

Vanderstoep, S., \& Johnson, D. (2008). Research methods for everyday life: Blending qualitative and quantitative approaches. John Wiley \& Sons.

Vatterott, C. (2018). Rethinking homework: Best practices that support diverse needs. ASCD.

Webb, A., \& Moallem, M. (2016). Feedback and feed-forward for promoting problem-based learning in online learning environments. Malaysian Journal of Learning and Instruction, 13(2), 1-41.

Williams, J., \& Takaku, S. (2011). Help seeking, self-efficacy, and writing performance among college students. Journal of Writing Research, $3(1), 1-18$.

Wolters, C., Won, S., \& Hussain, M. (2017). Examining the relations of time management and procrastination within a model of self-regulated learning. Metacognition and Learning, 12(3), 381-399. https://doi. org/10.1007/s11409-017-9174-1

$\mathrm{Xu}, \mathrm{J}$. (2008). Validation of scores on the homework management scale for high school student. Educational and Psychological Measurement, 68(2), 304-324. https://doi.org/10.1177/0013164407301531

$\mathrm{Xu}$, J. (2011). Homework completion at the secondary school level: A multilevel analysis. The Journal of Educational Research, 104(3), 171182. https://doi.org/10.1080/00220671003636752

Xu, J., Yuan, R., Xu, B., \& Xu, M. (2014). Modeling students'time management in math homework. Learning and Individual Differences, 34, 33-42. https://doi.org/10.1016/j.lindif.2014.05.011

Zhu, Y., \& Leung, F. (2012). Homework and mathematics achievement in Hong Kong: Evidence from the TIMSS 2003. International Journal of Science and Mathematics Education, 10(4), 907-925. https://doi. org/10.1007/s10763-011-9302-3

Zimmerman, B. (2000). Attaining self-regulation: A social cognitive perspective. In M. Boekaerts, M. Zeidner \& P. Pintrich (Eds.), Handbook of self-regulation (pp. 13-39). USA, Elsevier.

Zimmerman, B., \& Campillo, M. (2003). Motivating self-regulated problem solvers. In J. Davidson, R. Sternberg \& R. Sternberg (Eds.), The psychology of problem solving (pp. 233-362). Cambridge University Press. 
Zimmerman, B., \& Moylan, A. (2009). Self-regulation: Where metacognition and motivation intersect. In D. Hacker, J. Dunlosky \& A. Graesser (Eds.), Handbook of metacognition in education (pp. 311-328). Routledge. 